\title{
The Modern Approach to Guide Surgical Coronary Revascularization
}

\author{
Almas Tolegenuly ${ }^{1}$ \\ ${ }^{1}$ Affiliation not available
}

July 16, 2021

\begin{abstract}
Coronary revascularization is crucial in the treatment of ischemic heart disease (IHD) patients because it relieves symptoms with managing adverse outcomes, including myocardial infarction (MI). To decide on revascularization of the coronary artery, it is necessary to have diagnostic evidence, since only the coronary vessels causing ischemia must be selected for revascularization. Hence, in order not to subject patients to unnecessary revascularization and to treat with medical therapy, accurate measurements of the significance of coronary artery stenosis are necessary. Identifying stenoses that cause ischemia should be achieved in a variety of ways that include invasive and non-invasive tests. Cardiologists use a combination of these investigations together for optimal further treatment. The purpose of this review was to describe publicly available data on recommendations to guide surgical coronary revascularization.
\end{abstract}

The Modern Approach to Guide Surgical Coronary Revascularization

Running title: Guiding Surgical Coronary Revascularization

Almas Tolegenuly*

*Department of Cardiac Surgery, National Scientific Medical Center, Nur-Sultan city, Republic of Kazakhstan

\section{Corresponding author:}

Almas Tolegenuly, Department of Cardiac Surgery, National Scientific Medical Center, Nur-Sultan city, 010000; Republic of Kazakhstan Email address: almas.tolegenuly@gmail.com

\section{Abstract}

Coronary revascularization is crucial in the treatment of ischemic heart disease (IHD) patients because it relieves symptoms with managing adverse outcomes, including myocardial infarction (MI). To decide on revascularization of the coronary artery, it is necessary to have diagnostic evidence, since only the coronary vessels causing ischemia must be selected for revascularization. Hence, in order not to subject patients to unnecessary revascularization and to treat with medical therapy, accurate measurements of the significance of coronary artery stenosis are necessary. Identifying stenoses that cause ischemia should be achieved in a variety of ways that include invasive and non-invasive tests. Cardiologists use a combination of these investigations together for optimal further treatment. The purpose of this review was to describe publicly available data on recommendations to guide surgical coronary revascularization.

Keywords: Coronary Artery Bypass Grafting; Instantaneous Wave-Free Ratio; Fractional Flow Reserve; Quantitative Flow Ratio

\section{Hosted file}


Body.docx available at https://authorea.com/users/425958/articles/530630-the-modernapproach-to-guide-surgical-coronary-revascularization 